Original Research Paper

\title{
Hardening Effects of In-Situ Aging for a Laser Welded Maraging Steel
}

\author{
Milton Sergio Fernandes de Lima, Rafael Humberto de Mota Siqueira, \\ Sheila Medeiros de Carvalho and Antonio Jorge Abdalla \\ Photonics Division, Institute for Advanced Studies, 12.228-001 São Jose dos Campos, Brazil
}

Article history

Received: 07-10-2019

Revised: 06-11-2019

Accepted: 11-11-2019

Corresponding Author:

Milton Sergio Fernandes de Lima

Photonics Division, Institute for Advanced Studies, 12.228-001 São Jose dos Campos, Brazil Email: msflima@gmail.com

\begin{abstract}
Maraging steels are ultra-high strength alloys which have been successfully laser welded to obtain structural components. For most of the applications these steels are in an aged state to attain tensile strength up to $1.5 \mathrm{GPa}$, although welding induces local softening due to dissolution of precipitates. This paper aims to investigate the effect of in-situ aging of the maraging steel plates after laser welding to reduce the local softening. For a preheating at $40^{\circ} \mathrm{C}$, just below the martensite finish line, the hardness of the Fusion Zone (FZ) attained between 440 and $490 \mathrm{HV}$ and the Heat-Affected Zone (HAZ) attained a maximum of $570 \mathrm{HV}$ compared to $300 \mathrm{HV}$ of the Base Material (BM) for aging temperatures between $450^{\circ} \mathrm{C}$ and $520^{\circ} \mathrm{C}$ and periods between 10 and 30 min. The intercritical aging $\left(570^{\circ} \mathrm{C} / 1 \mathrm{~h}\right)$ also promoted an increase in local hardness of FZ $320 \mathrm{HV}$ and HAZ $400 \mathrm{HV}$. Using an intercritical aging, the hardness situated between room temperature and quenched and aged coupons and was more homogeneous considering FZ, HAZ and BM. The microstructure of the intercritical aged welds is marked by duplexferrite and martensite micro-constituents.
\end{abstract}

Keywords: Maraging Steels, Laser Beam Welding, Post-Welding Heat Treatment, Aging

\section{Introduction}

Maraging alloys belong to the Ultra-High Mechanical Strength Steels (UHSS) as could attain tensile strengths up to $3.4 \mathrm{GPa}$ depending on composition and the thermomechanical treatments (Rohrbach and Schmidt, 1993). Different from ordinary UHSS, Maraging steel martensite is ductile and the maximum strength is obtained by aging (Silva et al., 2019). The phase transformations for produce the steel ingots are the origin of the name MARtensite and AGING. Bieber (1969) was the first to prove that a $\mathrm{Fe}-25 \% \mathrm{Ni}-4 \% \mathrm{Ti}-$ $4 \% \mathrm{Al}$ steel attained a maximum tensile strength of 1 $\mathrm{GPa}$ after aging at $480^{\circ} \mathrm{C}$ during $160 \mathrm{~min}$.

Although Maraging steels proved their usefulness in high demanding applications such as rocket bodies, high pressure tanks and landing gears, welding is still a challenge (Rajkumar et al., 2014). Fusion welds solubilizes the precipitates into the austenite matrix and produce softened weld zones (Fanton et al., 2014). Even with solid state processes failed to prevent softening of the joint because annealing produces fully martensite in cooling (Kellogg, 2012).
Silva et al. (2019) heat treated a class 300 Maraging steel from 1 to $100 \mathrm{~h}$ at $440^{\circ} \mathrm{C}$ obtaining hardness ranging from $300 \mathrm{HV}$ to $620 \mathrm{HV}$. These authors recorded the Moessbauer spectra for each aging time and noted that a high mobility of Mo and $\mathrm{Ti}$ atoms for times under $3 \mathrm{~h}$.

The present investigation proposes an inductive heating together with the laser weld of Maraging 300 steels in order to produce aging directly in the final product. One difference of the current approach to the conventional heat treating is that the material is not normalized prior to aging. It is expected that Base Material (BM) and the Heat-Affected Zone (HAZ) austenitize rapidly during laser heating. However, the Fusion Zone (FZ) of the welds present microsegregation which will produce composition modulations retained during aging. These assumptions are corroborated by Casati et al. (2016).

Inductive heating in laser welding had been already used to increase the cooling period of EN 10025-6 S690QL fine-grained structural steel (Lahdo et al., 2014) and to produce bainite in hot-stamping steels (Lima et al., 
2017). However, to the best knowledge of the authors, it is the first time aging is applied concomitant to laser welding of maraging steels.

Krasnikova et al. (1986) reported that the interdendritic region of as-cast ingots of 250 maraging are rich in $\mathrm{Ti}$ and Mo. These segregations induce the formation of $\delta$-ferrite precipitates and to a depletion of these elements in the dendrite trunks. Linnert (1967) stated that reducing these elements in the $\mathrm{Fe}-\mathrm{Ni}$ tempered martensite reduces the mechanical strength due to a decrease in precipitation hardening potential. These findings were also pointed out by Pektas and Atala (1998) which indicated a high temperature solution treatment, e.g., $1000^{\circ} \mathrm{C} / 4 \mathrm{~h}$, aiming to reduce the elements segregation.

The temperatures for the isothermal treatment, i.e., $450^{\circ} \mathrm{C}, 480^{\circ} \mathrm{C}$ e $520^{\circ} \mathrm{C}$, were determined in a previous study (Lombardo et al., 2016). According to Pektas and Atala (1998), $18 \% \mathrm{Ni}$ maraging steels present a good balance between tensile strength and toughness when aged at $480^{\circ} \mathrm{C}$ per $4 \mathrm{~h}$. The maximum temperature of austenite precipitation was chosen according to Kapoor et al. (2003) at $570^{\circ} \mathrm{C}$ as the maximum density of precipitates measured by dilatometric tests in $18 \mathrm{wt} . \%$ Ni maraging steel of grade 350 .

One way to understand the martensitic transformation in maraging steels is to start with the metastable phase diagram, Fig. 1. From the solidification, there is no transformation of the austenite phase in the steel before it reaches the Martensite Start (Ms) temperature. Some studies show that the martensitic transformation always operates on 300 maraging steels, even when the cooling rate is quite slow, as well as in large parts. The resulting martensite has a center body cubic structure, as opposed to the hexagonal structure of the common martensites of the steels, due to the low carbon content. Martensite is relatively ductile, $0 \sim 30 \mathrm{HRC}$ and has a high dislocation density without significant twining. Alloy elements change Ms but do not alter the fact that the martensitic transformation is independent of the cooling rate (ASM Handbook Committee, 1990a). The great majority of the alloying elements and in particular the $\mathrm{Ni}$, decrease the transformation temperature Ms. Cobalt is an exception because it increases Ms. The addition of Co is precisely to balance the decrease in Ms of the alloying elements, e.g., $\mathrm{Ni}, \mathrm{Ti}, \mathrm{Mo}$, which are required for precipitation during aging.

According to common practice, aging hardening is carried out at temperatures between 455 and $510^{\circ} \mathrm{C}$ for 3 to $9 \mathrm{~h}$, followed by air cooling. From the phase diagram, blue lines in Fig. 1, 42\% of ferrite is obtained for an $18.5 \% \mathrm{Ni}$ composition and a temperature of $500^{\circ} \mathrm{C}$. A reversion to an austenitic-ferrite structure would hinder precipitation hardening. However, the enthalpy for precipitation of intermetallic phases is smaller than the reversal for a ferrite-austenite mixture. For example, for the current alloy and according to ThermoCalc computations, the equilibrium phases at $475^{\circ} \mathrm{C}$ are: Iron ferrite $\left(92 \%\right.$ mole), $\mathrm{Ni}_{3} \mathrm{Ti}$ (3\% mole), FeCr $\left(3 \%\right.$ mole) and $\mathrm{Cu}_{0.76} \mathrm{Ti}_{0.23}$ (1\% mole) (Sha, 2000). Therefore, there is a precipitation of phases inside the grains with martensitic structure in plates aided greatly by the high density of dislocations. The distribution of particles consistent with the matrix is uniform and the main hardeners are Ti-based.



Fig. 1: Pseudobinary phase diagram for the solid state transformations in Maraging 300 steel (ASM Handbook Committee, 1990a) 
The phase with the least distortion (misfit) in the CCC matrix of martensite is $\mathrm{Ni}_{3} \mathrm{Ti}$ and therefore privileged in the initial states. The precipitation has a limit given by the solute diffusivities and high aging times tend to form the so-called reversed austenite. Overaging causes an expressive reduction of the hardness of the steel and is fundamentally the reversion to the thermodynamic equilibrium in the intercritical zone (Fig. 1). The most probable mechanism of reversed austenite formation is the dissolution of nickel-rich precipitates, which enriches the matrix and renders the austenite more thermodynamically stable. The red lines in Fig. 1 presents the experimental limits (ASM Handbook Committee, 1990a) for Austenite reversion on Heating (Ah) and Martensite formation on Cooling (Mc) together with the current initial Ni composition.

\section{Experimental}

The material was received as an $18 \% \mathrm{Ni}$ class 300 Maraging steel from Böhler Co. in the form of $3.3 \mathrm{~mm}$ thick plates. The composition is given in Table 1 and agrees with the SAE AMS 6514F standard (SAE Mobilus, 2019). The material was hot rolled and air-cooled resulting in a relatively soft martensite $(330 \mathrm{HV})$.

The laser workstation is composed of an YLR-2000 IPG Photonics fiber Laser, a CNC table, a furnace and auxiliary systems. The laser minimum spot is $0.1 \mathrm{~mm}$ and the beam quality is $\mathrm{M}^{2}=9$. The $\mathrm{CNC}$ table is driven by three step motors with maximum speed of $160 \mathrm{~mm} / \mathrm{s}$ and processing area of $400 \times 500 \mathrm{~mm}^{2}$. The furnace was conceived for inductive heating during the welds as previously reported in the literature (Lima et al., 2017). The auxiliary systems comprise water cooled jackets and nitrogen cross jet to protect the optics.

The welds were realized bead-on-plate with the focus on the top of the upper surface. The surfaces were grounded and cleaned with ethanol prior to the welds. After the focus position was calibrated $50 \times 50 \mathrm{~mm}^{2}$ samples of the steel were positioned in the center of the furnace. The samples were inductively heated up to a given temperature and maintained at these temperatures with the use of a manual switch. One thermocouple welded to the bottom surface of the plate recorded the temperature profile. The furnace and laser setup were reported elsewhere (Braga et al., 2018).

Since the steel plates were inserted in a furnace, a protective atmosphere was not possible. However, previous results have shown that the porosity due to the atmospheric contamination is high only for full penetration welds, i.e. when the fusion zone attains the lower surface of the plate. In view of this, the laser power and weld speed were conceived for partial penetration. For the current experimental conditions, the laser power was fixed at $1800 \mathrm{~W}$ and the weld speeds were $1.8,2.4$ and $3.0 \mathrm{~m} / \mathrm{min}$ in accordance to a previous work (Sakai et al., 2015).
Table 1: Chemical composition of the base material (wt.\%). $\mathrm{Fe}$ as the balance

\begin{tabular}{llllllll}
\hline $\mathrm{C}$ & $\mathrm{Si}$ & $\mathrm{Mn}$ & $\mathrm{Ni}$ & $\mathrm{Mo}$ & $\mathrm{Co}$ & $\mathrm{Al}$ & $\mathrm{Ti}$ \\
\hline 0.005 & 0.05 & 0.05 & 18.5 & 5.0 & 8.8 & 0.11 & 0.70 \\
\hline
\end{tabular}

The microstructure of the samples was analyzed by a Light Optical Microscopy (LOM) using an Imager.2M Zeiss microscope and Nital 2\% etching. Scanning electron microscopy was carried out using a Hitachi TM3000 microscope. An equipment model FM800 (Futuretech) was used for Vickers hardness tests using $100 \mathrm{gf}$ load and a dwell time of 10 seconds.

For thermodynamic calculations using the ThermoCalc $\odot$ software, the TCFE6-steel database was used (Andersson et al., 2002). The thermal simulation was carried out using Sysweld $\odot$ Software (Esi-Group, 2019). Sysweld is a Finite Element Modeling (FEM) software specially designed for welding and heat treatment of metals and alloys. For the current purpose a mesh refined around the laser path was designed with a lateral resolution of about $0.001 \mathrm{~mm}$. The exact maraging 300 properties are not available in the Sysweld database, therefore $\mathrm{X} 5 \mathrm{CrNi} 1810$ (EN 1.4301) steel properties were used instead. The model dimensions and welding procedure followed those described in the experimental design, starting with the material at room temperature and heating it up to a given temperature $T^{*}$. The software produces many valuable outputs, but those of interest here are the time-temperature evolution in different regions of the plate.

\section{Results and Discussion}

\section{Ambient Temperature Welds}

Figure 2 presents cross-section images of representative welds obtained for speeds of 1.8, 2.4 and $3.0 \mathrm{~m} / \mathrm{min}$. In a general view, the welds were thinner and deeper as the speed varies from 1.8 to $3.0 \mathrm{~m} / \mathrm{min}$. The weld obtained at $1.8 \mathrm{~m} / \mathrm{min}$ has a top width of $2.2 \mathrm{~mm}$ and penetration of $2.5 \mathrm{~mm}$, compared to the weld obtained at $3.0 \mathrm{~m} / \mathrm{min}$ with a top width of $1.2 \mathrm{~mm}$ and penetration of $2.7 \mathrm{~mm}$. As the welds were performed without gaseous protection, the plasma generated on the surface of the plate is more intense with slower speed, since the interaction time increases and more metallic ions are present. Additionally, as speed increases, the plasma plume tends to move back from the center of the keyhole, allowing the incident beam to penetrate further into the plate. This effect is known and reported as a function of the gas flow, causing the plasma to move away from the center of the beam (Joseph et al., 2017).

The extent of HAZ is a function of the welding speed, although it varies depending on the region where it is measured. In the case of the macrographs shown in Fig. 2 the HAZ ranges between 0.7 and $0.4 \mathrm{~mm}$, from 
1.8 to $3.0 \mathrm{~m} / \mathrm{min}$. This region is equivalent to the limit of dissolution of intermetallic precipitates responsible for the hardening of the material. From the FEM simulations, the limit of the HAZ represents an isotherm of $900^{\circ} \mathrm{C}$.

It is expected that microsegregation appears among the dendritic branches of the fusion zone (Fig. 3). In the figure, the central region is composed of equiaxed dendrites spaced $3 \mu \mathrm{m}$ and where $39 \%$ were interdendritic material. These values did not change significantly in the current speed interval.

Figure 4 presents the time-temperature profile for each speed condition estimated in the middle of the fusion zone. Each curve is displaced in time for better visualization. According to the thermodynamic database Thermocalc (Andersson et al., 2002), the liquidus temperature is $1417^{\circ} \mathrm{C}$, also displayed in Fig. 4. For every condition, the liquid was superheated above $1900^{\circ} \mathrm{C}$ and the cooling rates at liquidus were estimated

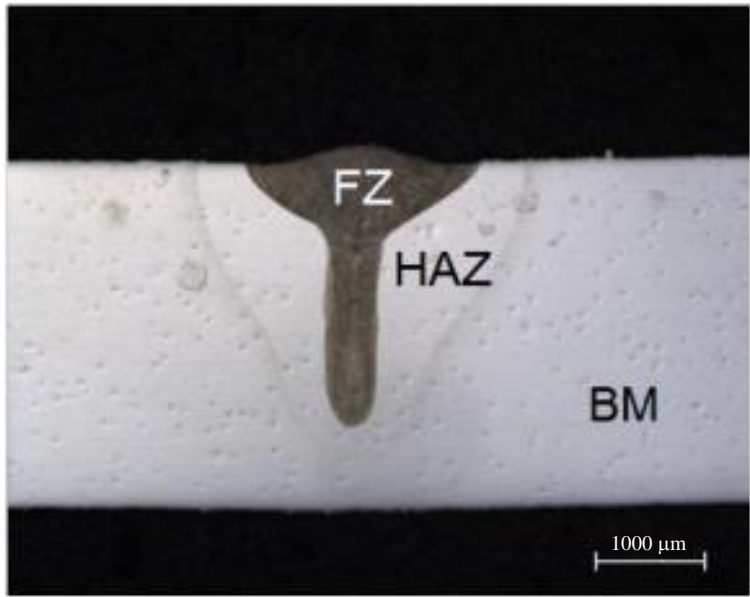

(a) $16^{\prime} 300,22^{\prime} 500,25^{\prime} 700^{\circ} \mathrm{C} / \mathrm{s}$ for $1.8,2.4$ and $3.0 \mathrm{~m} / \mathrm{min}$, respectively. Near to $760^{\circ} \mathrm{C}$, the cooling rates are $4^{\prime} 000$, $5^{\prime} 700, \quad 6^{\prime} 900^{\circ} \mathrm{C} / \mathrm{s}$ for $1.8,2.4$ and $3.0 \mathrm{~m} / \mathrm{min}$, respectively, which are large enough to produce martensite transformation with a Vickers hardness of 313 HV (ASM Handbook Committee, 1990b).

The actual hardness profiles of the samples are presented in Fig. 5. The Fusion Zone (FZ) hardness (open squares in Fig. 5) situated between 280 and 300 $\mathrm{HV}$, consistent with an unaged martensite structure. The Heat-Affected Zone (HAZ) hardness (crossedsquares in Fig. 5) is typically above the FZ Vickers hardness because of the solid-state transformation implies in the absence of microsegregation. Finally, the Base Material (BM) is delimited by the temperature below the austenite reversion on heating (Fig. 1). The rise in $\mathrm{HV}$ for the $\mathrm{BM}$ near to the $\mathrm{HAZ}$ is due to local ageing of the original martensite.

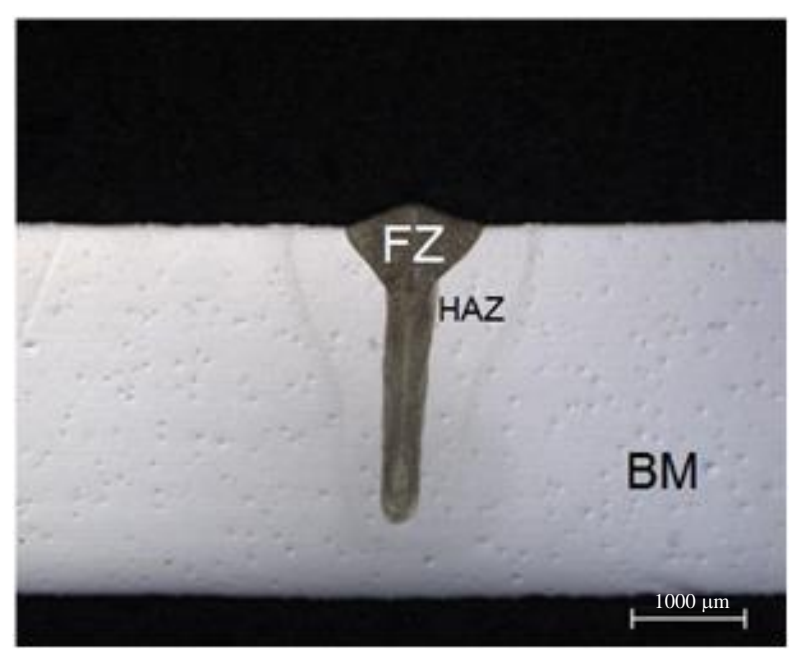

(c)

Fig. 2: Macroscopic view of the welds at different speeds: (a) $1.8 \mathrm{~m} / \mathrm{min}$; (b) $2.4 \mathrm{~m} / \mathrm{min}$ e (c) $3.0 \mathrm{~m} / \mathrm{min}$ 




Fig. 3: Microstructure observed at the center of the bead. Speed $1.8 \mathrm{~m} / \mathrm{min}$

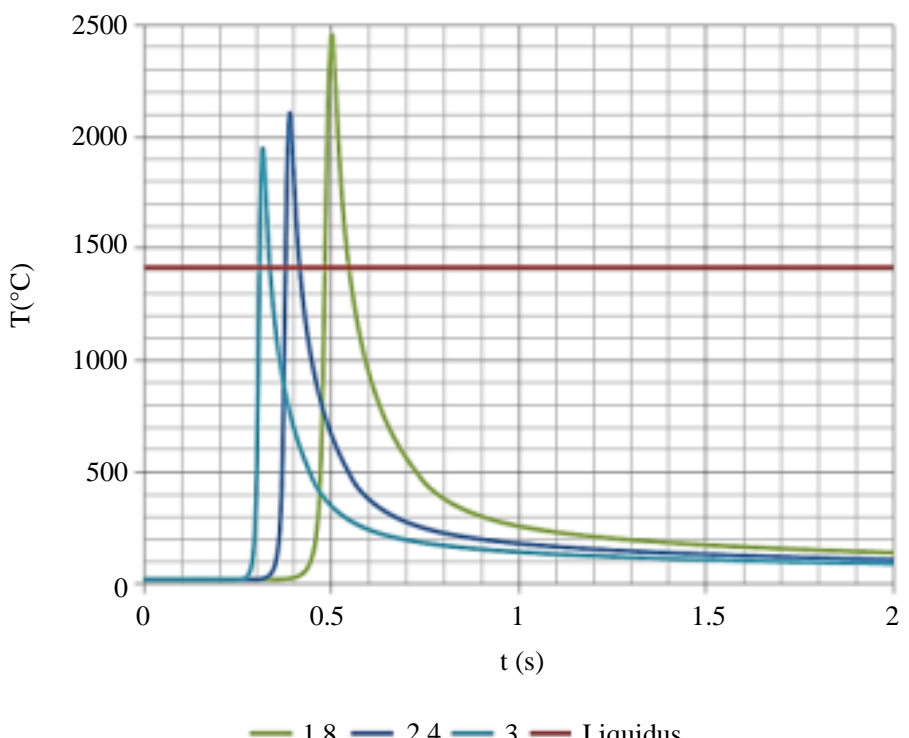

Fig. 4: Prediction of the temperature as a function of the time in the center of the welds according to SysWeld software. Room temperature laser welding for welding speeds: $1.8,2.4$ and $3.0 \mathrm{~m} / \mathrm{min}$. The liquidus line is represented as well

\section{Quenching and Aged Welds}

Quenched and aged welds are those heat-treated subsequent to complete quenching, as presented in Fig. 6. The temperature profile came from Sysweld simulation (laser weld) and from the thermocouple records when the time is above 10 seconds. For the welding, only one condition ( $3 \mathrm{~m} / \mathrm{min}$ ) had been chosen, although the time and temperature for isothermal aging was changed. Figure 6 also presents the temperatures for austenite reversion in heating (Ah) and Martensitic transformation in Cooling (Mc). The isothermal aging was conceived to occur between the Ah and Mc lines, in accordance to previous works (Fanton et al., 2014).
Figure 7 presents the macrographies of the welded regions and surroundings as a function of the aging time and temperature. The weld shapes resemble those obtained in ambient temperature conditions (Fig. 2), although the penetration attained the bottom surface in a majority of cases. Since the furnace configuration does not support a protective gas nozzle, the enhanced weld penetration could be associated to a better plasma coupling or to the absence of surface cooling induced by the flowing argon. Also, the HAZ is more distinctive in Fig. 7 compared to Fig. 2 because of precipitation of intermetallic compounds. 

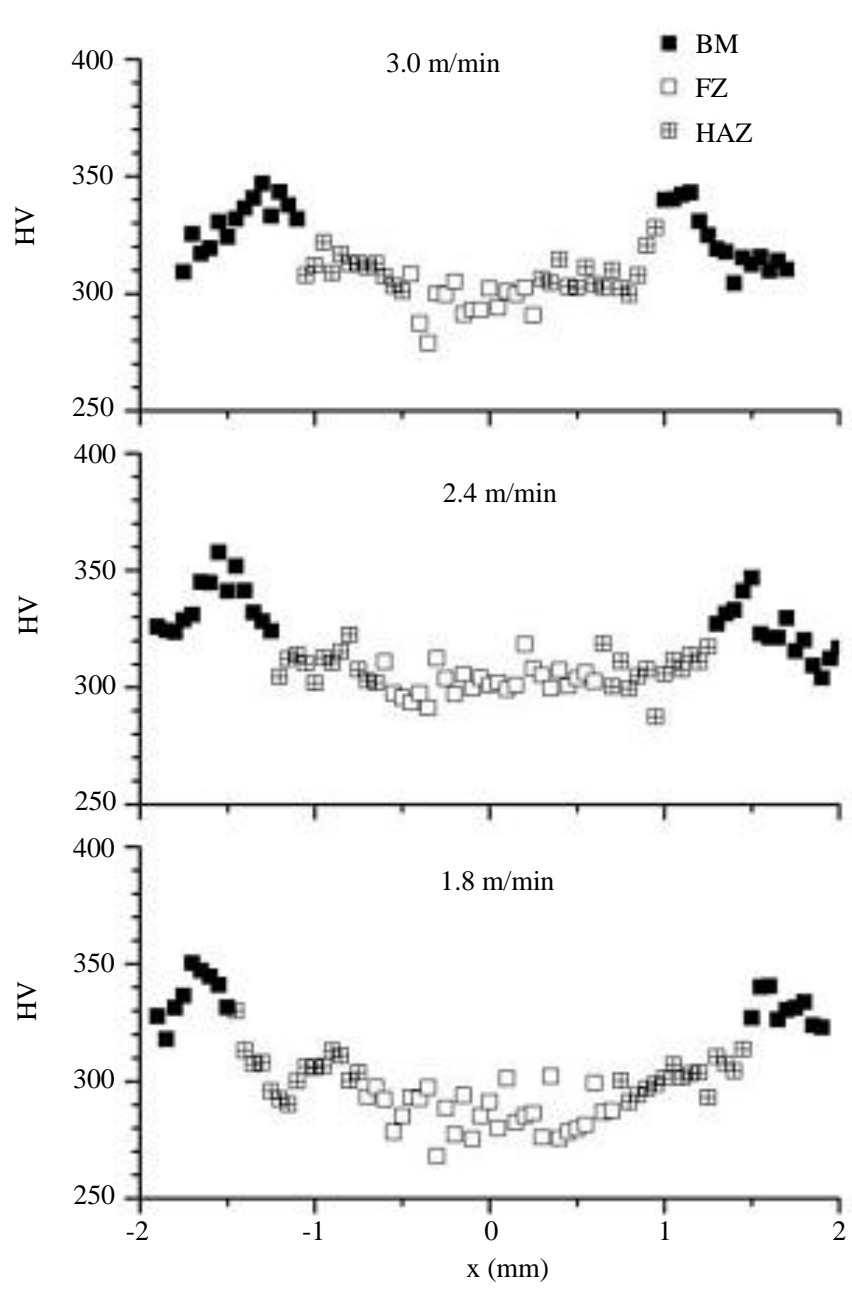

Fig. 5: The Vickers hardness profiles of the welds obtained in different speeds at room temperature. The FZ, HAZ and BM are indicated by different symbols

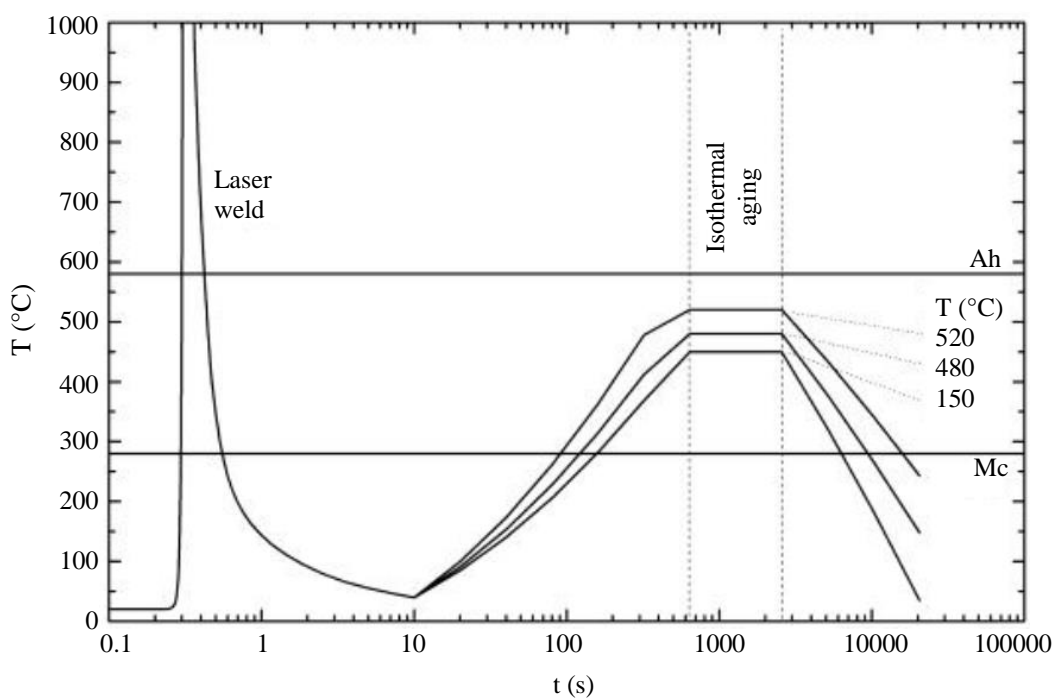

Fig. 6: The temperature profile for the quenched and aged. Although the isothermal period was changed from 10 to 30 min, only the $30 \mathrm{~min}$. isotherm is shown. The time is plotted in logarithm scale for clearness 
The intermetallic precipitation noticed for the ambient temperature welds (Fig. 3) is still visible in the welds after aging (Fig. 8a). Although a partial solubilization of the microsegregation after an aging of $520^{\circ} \mathrm{C}$ per $10 \mathrm{~min}$ promoted a skeleton-type distribution. The aged martensite is also visible in Fig. 8a, with the precipitates removed by the chemical etching. Figure $8 \mathrm{~b}$ shows a region near the Fusion Line (FL) where the same features of the weld centerline could be seen at the right. At the left, aged martensite grains are free of massive precipitates as those observed in the FZ.

The hardness profiles for each aging condition are plotted in Fig. 9 as a function of the region: FZ, HAZ and BM. As reported before (Sakai et al., 2015), the general tendency is an increase in HV when increasing aging time or the temperature. However, the FZ values are distinctly below the other regions HV. As presented before, Fig. 8, the heat treatment was not sufficient to homogenize the as-solidified precipitates at the interdendritic region. Some important elements for nucleation during aging, particularly $\mathrm{Ti}$ and $\mathrm{Mo}$, are depleted in the martensite matrix and therefore the FZ tempered martensite is softer than other regions. The hardness obtained in BM and HAZ are the same because of the initial homogeneous structure.

After $30 \mathrm{~min}$ the average hardness of BM and HAZ attained approximately 510, 520 and $570 \mathrm{HV}$ for temperatures of 450,480 and $520^{\circ} \mathrm{C}$, respectively. For the same temperatures the FZ attained considerably lower values of 440, 470 and $490 \mathrm{HV}$, respectively.

\section{Intercritical Aging}

Instead of quenching and aging the laser welded coupons, the intercritical aging aimed to heat the steel plated between $\mathrm{Mc}$ and $\mathrm{Ah}$ in order to create a duplex structure $\alpha+\beta$ (Fig. 1). Figure 10 is a time-temperature plot composed of Sysweld results (laser weld) and the thermocouple record data (heating, isothermal aging and cooling). The temperature path was chosen slightly above the previous temperatures (Fig. 7) to maximize diffusion of the elements, but keep it below the austenite reversion on heating. The average isotherm is $570^{\circ} \mathrm{C}$, with a little period above Ah due to the laser heat input.

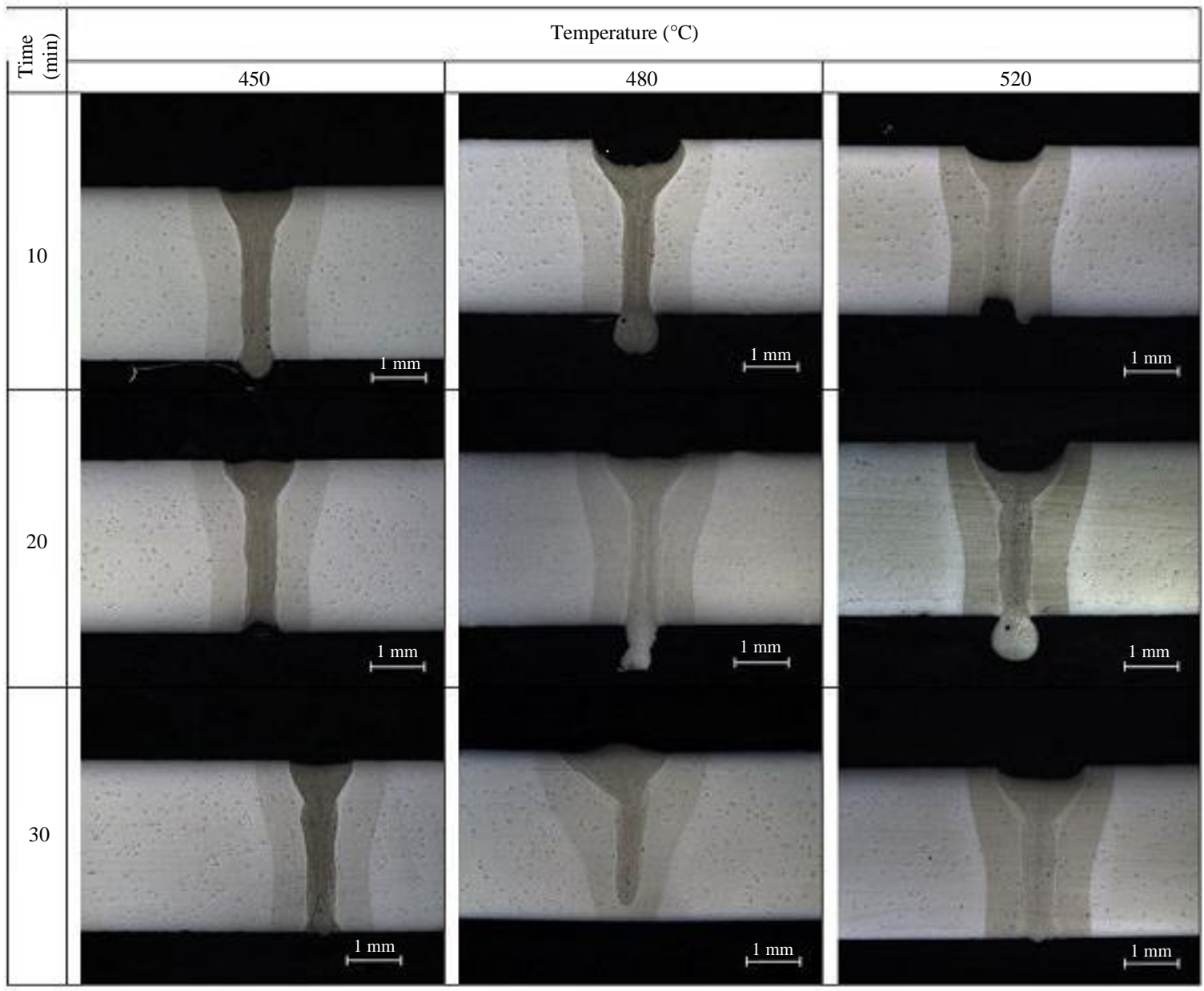

Fig. 7: General view of the cross section macrographs obtained in different aging temperatures and times 


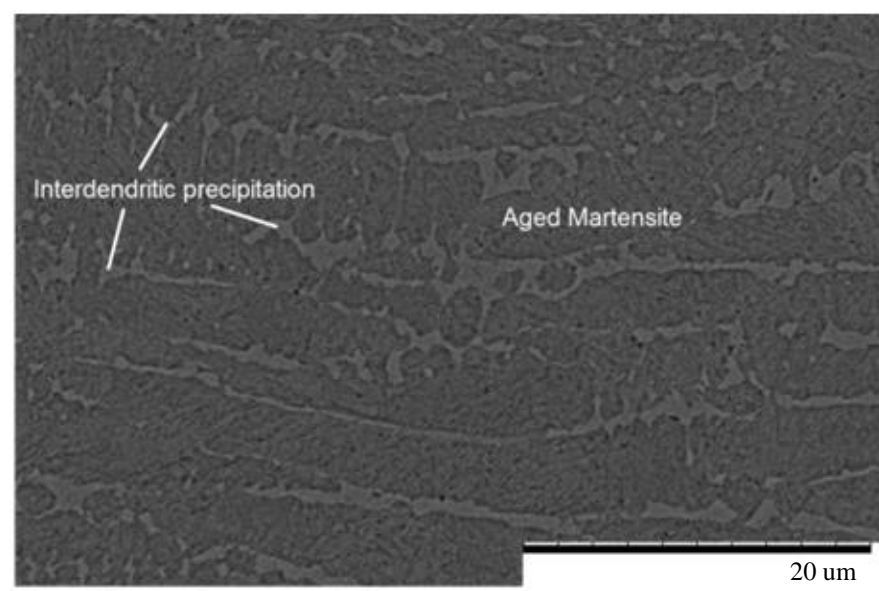

(a)

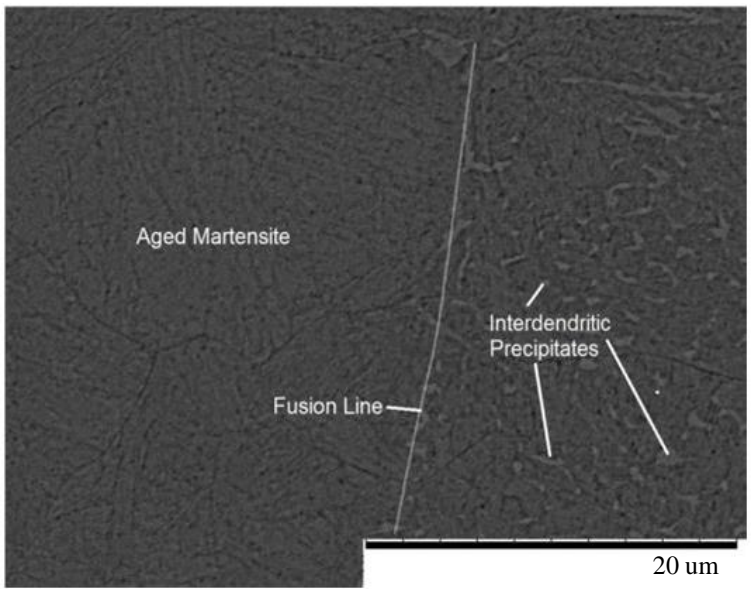

(b)

Fig. 8: Central region of the FZ (a) and the $\mathrm{HAZ}$ (b) for the welded and aged sample $\left(520^{\circ} \mathrm{C} / 10 \mathrm{~min}\right)$
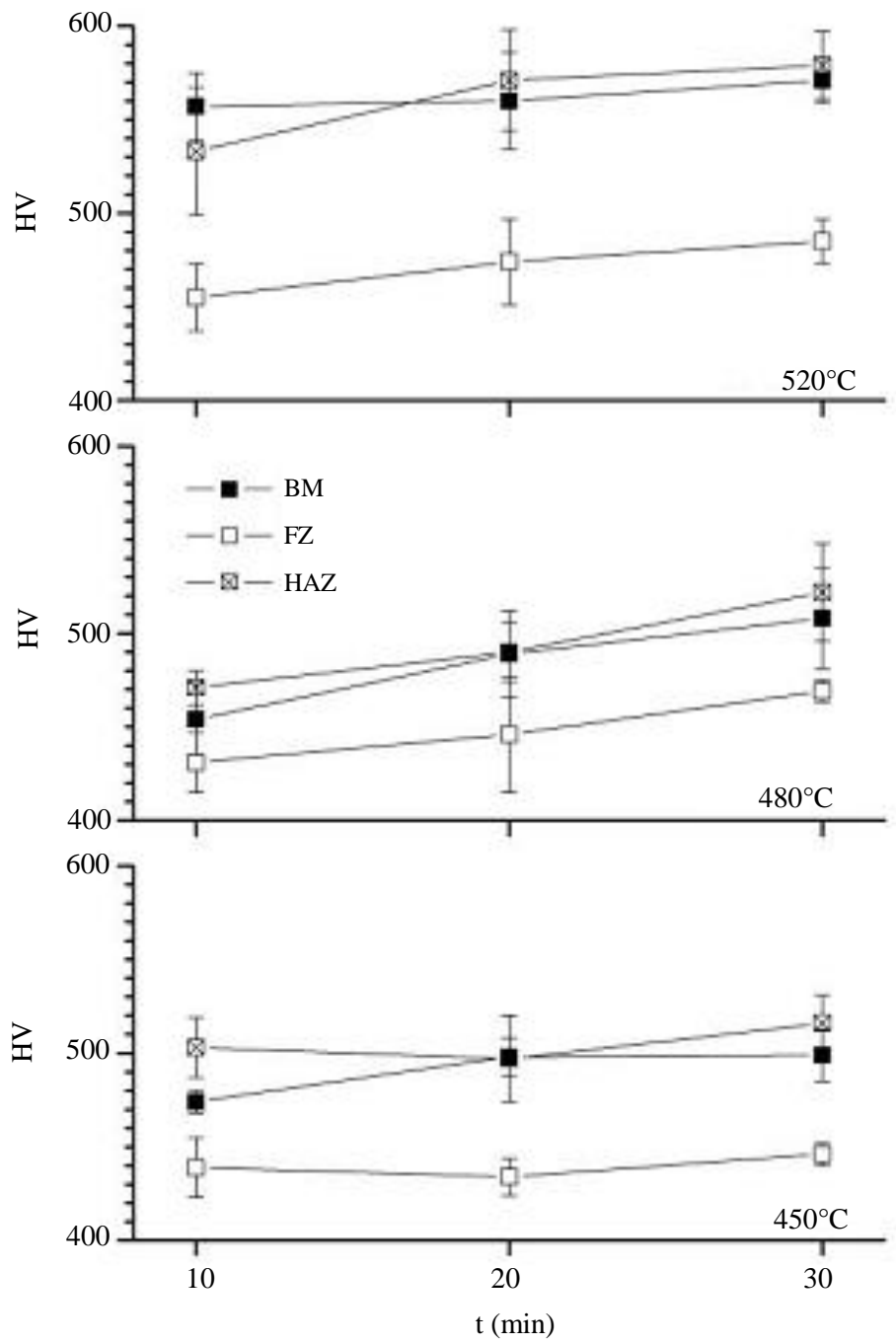

Fig. 9: Plots of the hardness profiles for the welded and aged samples 


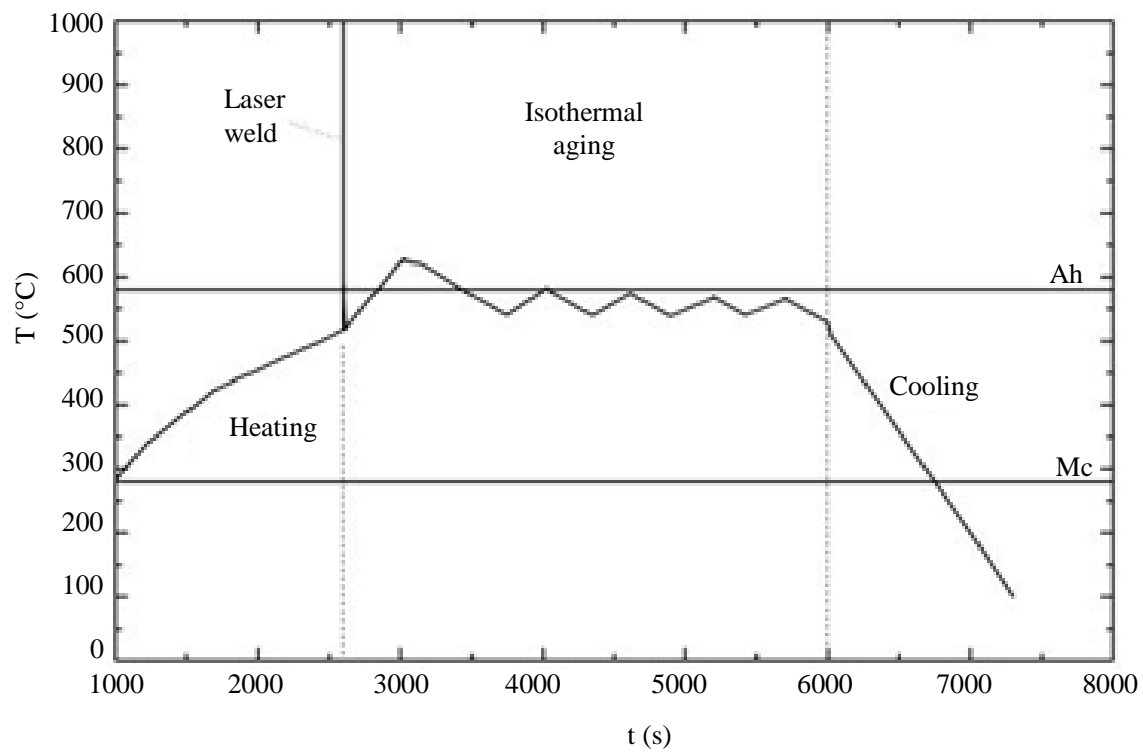

Fig. 10: Temperature evolution as a function of the time according to sysweld (weld) and a thermocouple record. Isothermal fixed at $570^{\circ} \mathrm{C}$

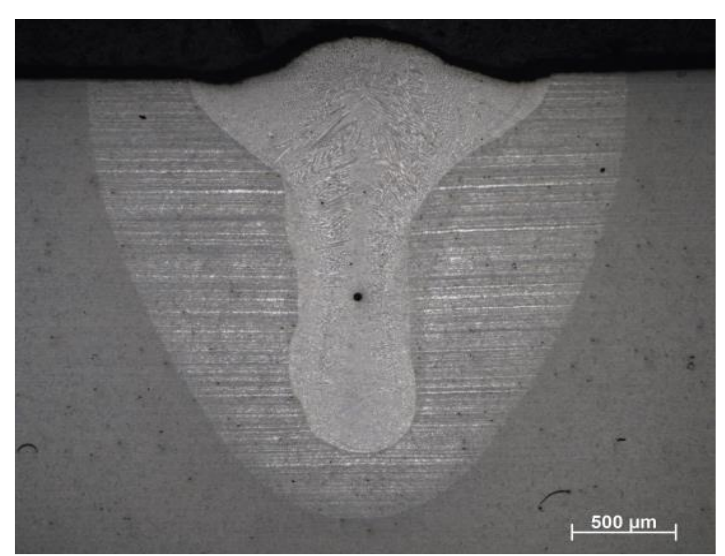

(a)

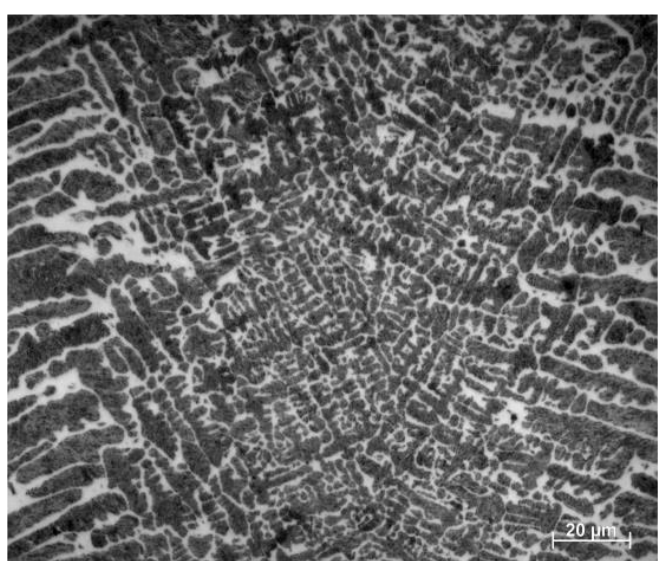

(b)

Fig. 11: (a) Macrostructure of in-situ aged weld and (b) microstructure at the middle of the FZ

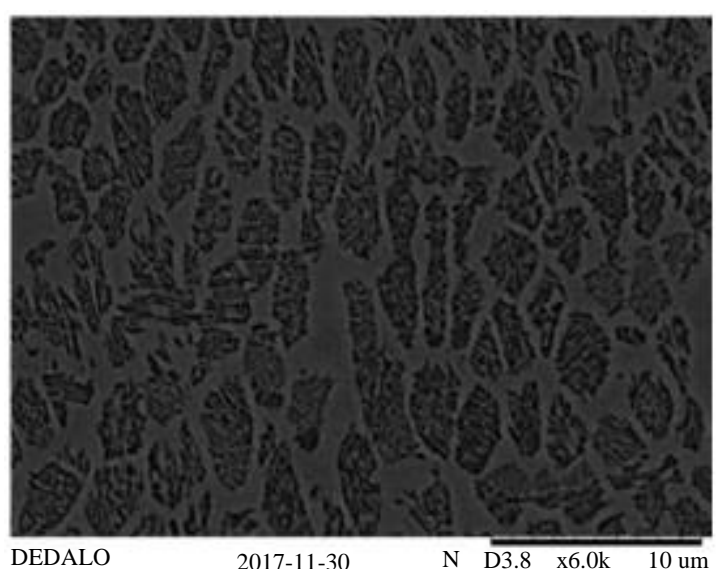

(a)

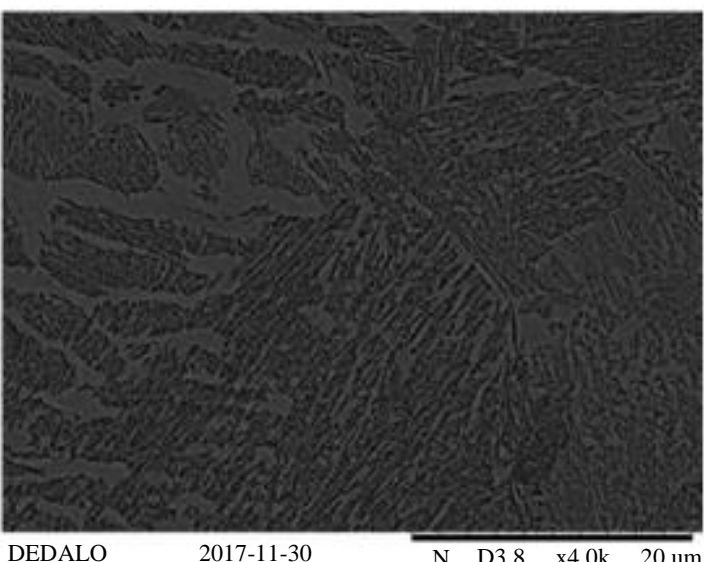

(b)

Fig. 12: Scanning electron microscopy (a) the microstructure near to the center of the FZ and (b) FZ/HAZ interfac 

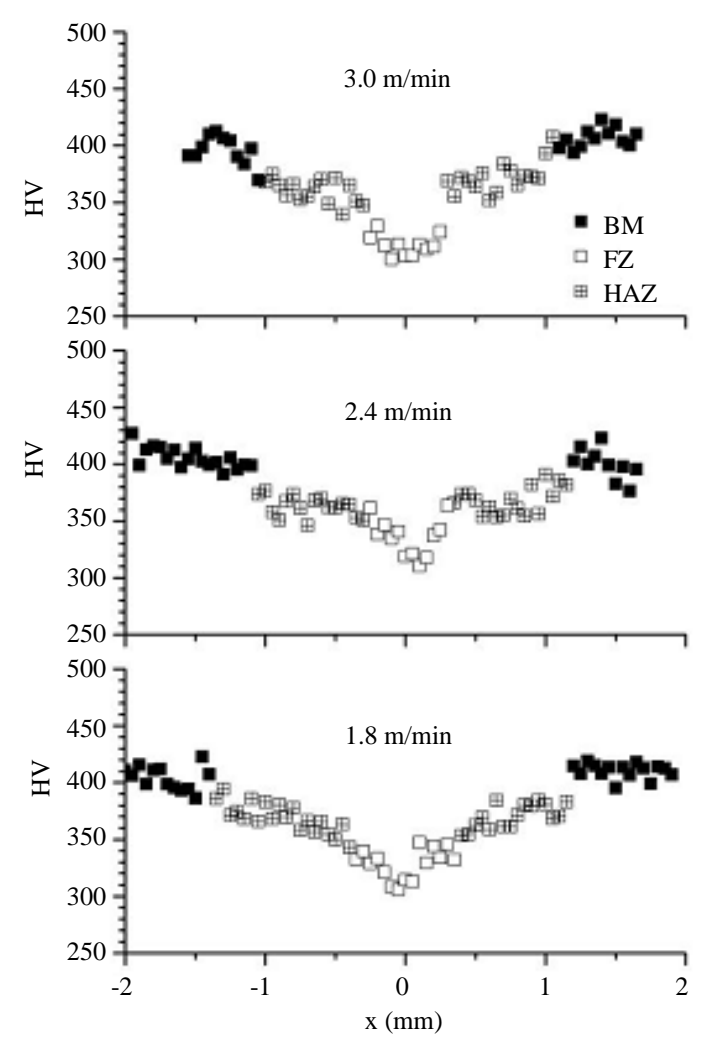

Fig. 13: The Vickers hardness profiles of the welds obtained in different speeds after in-situ aging. The FZ, HAZ and $\mathrm{BM}$ are indicated by different symbols

The weld macrostructure (Fig. 11a) and FZ microstructure (Fig. 11b) is very different from previous observations. The entire coupon was heat treated creating a flatter etching contrast (Fig. 11a). The FZ microstructure is composed by a light gray (ferrite) and dark gray (martensite) phases with calculated surface phase amounts of $43 \%$ ferrite and $57 \%$ martensite. Scanning electron images (Fig. 12a) indicated the ferrite phase occupies the former interdendritic spaces growing at expense of microsegregated phases. Figure $12 \mathrm{~b}$ is an image obtained near to the fusion line of the weld. In the figure, the HAZ ferrite growth occurred with a Widmanstätten morphology from the grain boundaries.

The hardness of the coupons (Fig. 13) lay between the room temperature welds (Fig. 5) and welded and aged samples (Fig. 9). The hardness range of all welding speeds was narrower than the welds without heat treatment, which could eventually lead to a decrease in stress concentrators.

\section{Conclusion}

This work compared the microstructure and hardness of maraging 300 plates obtained from room temperature weld, quenching and aging and intercritical aging with the use of a furnace coupled to a laser workstation.

The microstructure of room temperature welds is marked by dendrite growth, hence they present some microsegreation. This solute partitioning is responsible for the depletion in hardness in the weld compared to surrounding regions. The Fusion Zone (FZ) hardness situated between 280 and $300 \mathrm{HV}$, consistent with an unaged martensite structure. The Heat-Affected Zone (HAZ) hardness are typically above the FZ Vickers hardness because of the solid-state transformation implies in the absence of microsegregation. Finally, the Base Material (BM) is delimited by the temperature below the austenite reversion on heating.

When the welded coupons were quenched and aged in the range of temperatures 450 to $520^{\circ} \mathrm{C}$, with times from 10 to $30 \mathrm{~min}$, the aged martensite was observed. After 30 min the average hardness of BM and HAZ attained approximately 510, 520 and $570 \mathrm{HV}$ for temperatures of 450,480 and $520^{\circ} \mathrm{C}$, respectively. For the same temperatures the FZ attained considerably lower values of 440, 470 and $490 \mathrm{HV}$, respectively, due to the composition modulation.

Using an intercritical aging, the hardness situated between room temperature and quenched and aged coupons and are more homogeneous considering fusion zone, heat affected zone and base material. The microstructure of the intercritical aged welds is marked by duplex-ferrite and martensite microconstituents. The hardness range of all welding speeds was narrower than the welds without heat treatment, which could eventually lead to a decrease in stress concentrators.

\section{Acknowledgment}

This research has been supported by Fundação de Amparo à Pesquisa do Estado de São Paulo (FAPESP) under grant number 2016/16683-8.

\section{Author's Contributions}

Milton Sergio Fernandes de Lima: Managed the research and wrote the paper.

Rafael Humberto de Mota Siqueira: Conceived and designed the analysis; Performed the laser experiments.

Sheila Medeiros de Carvalho: Collected the simulation data; Performed the microstructural analysis.

Antonio Jorge Abdalla: Contributed analysis tools; Performed the mechanical analysis.

\section{Ethics}

The authors have declared no ethical issue of the publication of the present paper. 


\section{References}

Andersson, J.O., T. Helander, L. Höglund, P.F. Shi and B. Sundman, 2002. Thermo-calc and DICTRA, Computational tools for materials science. Calphad, 26: 273-312. DOI: 10.1016/S0364-5916(02)00037-8

ASM Handbook Committee, 1990a. Properties and Selection: Irons, Steels and High-Performance Alloys. 10th Edn., ASM, Metals Park (OH), ISBN-10: 0871703777, pp: 1063.

ASM Handbook Committee, 1990b. Heat Treating. ASM, Metals Park $(\mathrm{OH})$.

Bieber, C.G., 1969. Nickel Alloy. US. Patent No. 3,093,518, Filled Setember 11 .

Braga, V., R.A.F. Mansur, R.H.M. Siqueira and M.S.F. Lima, 2018. Formability of in-situ austempered transformation-induced plasticity steels after laser beam welding. Soldagem Inspeção, 23: 402-412. DOI: 10.1590/0104-9224/si2303.09

Casati, R., J.N. Lemke, A. Tuissi and M. Vedani, 2016. Aging behaviour and mechanical performance of 18-Ni 300 steel processed by selective laser melting. Metals, 6: 1-13. DOI: 10.3390/met6090218

ESI-group, 2019. ESI-group Sysweld Software.

Fanton, L., A.J. Abdalla and M.S.F. Lima, 2014. Heat treatment and yb-fiber laser welding of a maraging steel. Weld. J., 93: 362-368.

Joseph, A., H. Enguang, L. Chen, J. Dear and C. Davies, 2017. The effect of Ar and He shielding gas on fibre laser weld shape and microstructure in AA 2024-T3. J. Manufac. Process., 29: 62-73.

DOI: 10.1016/j.jmapro.2017.07.011

Kapoor, R., L. Kumar and I.S. Batra 2003. A dilatometric study of the continuous heating transformations in $18 \mathrm{wt} . \% \mathrm{Ni}$ maraging steel of grade 350. Mater. Sci. Eng. A, 352: 318-324. DOI: 10.1016/S0921-5093(02)00934-6

Kellogg, B., 2012. Friction stir welding and post-weld heat treating of 250-grade maraging steel. South Dakota School of Mines, Research Experience for Undergraduates, National Science Foundation.

Krasnikova, S.I., S.B. Vukelich, A.V. Drobot and A.Y. Shmelev, 1986. Dendritic inhomogeneity of stainless maraging steels. Mater. Sci. Heat Treat., 27: 781-786.

Lahdo, R., O. Seffer, A. Springer, S. Kaierle and L. Overmeyer, 2014. GMA-laser hybrid welding of high-strength fine-grain structural steel with an inductive preheating. Phy. Proc., 56: 637-645.

DOI: $10.1016 /$ j.phpro.2014.08.060

Lima, M.S.F., D. Gonzales and S. Liu, 2017. Microstructure and mechanical behavior of induction assisted laser welded AHS steels. Weld. J., 96: 376-388.
Linnert, G.E., 1967. Welding Metallurgy Carbon and Alloy Steel. 3rd Edn., AWS, New York, ISBN-10: 0686956052.

Lombardo, S., R.N. Ferreira. L.A.S. Santos, J.W.J. Silva and V. Scheid et al., 2016. Microstructural characterization of joints of maraging 300 steel welded by Laser and subjected to plasma nitriding treatment. Mater. Sci. Forum, 869: 479-483.

DOI: $10.4028 /$ www.scientific.net/MSF.869.479

Pektas, I. and H. Atala, 1998. The effects of various heat treating parameters on the hardness and microstructures of the experimental $18 \%$ nickel maraging steels. J. Thermal Analy., 54: 803-814. DOI: 10.1023/A:1010191820258

Rajkumar, V., N. Arivazhagan and R.K. Devendranath, 2014. Studies on welding of maraging steels. Proc. Eng., 75: 83-87. DOI: 10.1016/j.proeng.2013.11.017

Rohrbach, K. and M. Schmidt, 1993. Maraging Steels. In: ASM Metals Handbook: Properties and Selection: Irons, Steels and High-Performance Alloys. 2nd Edn., ASM International, Ohio.

Sakai, P.R., M.S.F. Lima, L. Fanton, C.V. Gomes and S. Lombardo et al., 2015. Comparison of mechanical and microstructural characteristics in maraging 300 steel welded by three different processes: LASER, PLASMA and TIG. Proc. Eng., 114: 291-297.

DOI: 10.1016/j.proeng.2015.08.071

Sha, W., 2000. Thermodynamic calculations for precipitation in maraging steels. Mat. Sci. Technol., 16: $1434-1436$. DOI: $10.1179 / 026708300101507415$

Silva, J.J.M., I.F. Vasconcelos, F.I.S. Silva, T.S. Ribeiro and H.F.G. Abreu, 2019. An atomic redistribution study of the $440^{\circ} \mathrm{C}$ ageing kinetics in maraging-300 steel. Mater. Res., 22: 1516-1439. DOI: 10.1590/1980-5373-mr-2018-0230

SAE Mobilus, 2019. Steel, maraging, bars, forgings, tubing and rings $18.5 \mathrm{Ni}-9.0 \mathrm{Co}-4.9 \mathrm{Mo}-0.65 \mathrm{Ti}$ 0.10Al Consumable Electrode Vacuum Melted, Annealed (AMS6514 Aerospace Material Specification)-SAE Mobilus. 